Tạp chí Khoa học và Công nghệ biển T10 (2010). Số 1. Tr 27 - 35

\title{
HÀM LƯợNG As, Pb TÍCH LŨY TRONG LOÀI HẾN (Corbicula sp.) VÀ HÀU SÔNG (Ostrea rivularis Gould, 1861) TẠI CỦA SÔNG CU ĐÊ, THÀNH PHỐ ĐÀ NÃ̃NG
}

\author{
NGUYẼ̃N VĂN KHÁNH, VÕ VĂN MINH, PHẠM TH!̣ HỒNG HÀ, DƯƠNG CÔNG VINH \\ Trường Đại học Sư phạm, Đại học Đà Nẵng
}

\begin{abstract}
Tóm tắt: Động vật hai mảnh vỏ rất phổ biến và đurợc ghi nhận là một loài chỉ thị sinh học tốt bởi vì nó có phân bố rộng và phổ biến ở nhiều thủy vực, có đời sống tĩnh, sức chống chịu tốt với ô nhiễm và tích lũy cao các chất ô nhiễm tù nước và trầm tích. Động vật hai mảnh vỏ đã được nghiên cứu để chỉ thị cho ô nhiễm KLN trong môi truò̀ng. Hơn nũa, công nghệ này dễ dàng đánh giá KLN tích lũy trong sinh vật, thuờng là cao hơn trong các thành phần khác, phản ánh được KLN linh động và có thể đi vào trong chuỗi thức ăn nhu là chất độc và gây độc hại đối với hệ sinh thái. Trong nghiên cưu này, chúng tôi trình bày kết quả nghiên cứu về tích lũy KLN As và Pb trong loài Hến (Corbicula sp.) và loài Hàu sông (Ostrea rivularis G.) tù cửa sông $C u$ Đê, TP. Đà Nẵng. Dũ liệu nghiên cứu này của chúng tôi góp phần quan trọng trong việc sủ̉ dụng loài Hến (Corbicula sp.) và loài Hàu sông (Ostrea rivularis G.) làm sinh vật chi thị ô nhiễm KLN.
\end{abstract}

\section{MỞ ĐÀ̀U}

Trong những năm gần đây, ô nhiễm kim loại nặng (KLN) do các hoạt động của con người gây ra có xu hướng gia tăng. KLN rất khó phân hủy trong môi trường, nó có khả năng gây ngộ độc tức thời hay ảnh hưởng lâu dài đến sức khỏe con người và các loài sinh vật [1]. Để quan trắc ô nhiễm KLN tại các vùng biển, vùng cửa sông phương pháp được sử dụng phổ biến là phân tích lý hóa trong nước hay bùn đáy (Phillips, 1977) [8]. Tuy nhiên, phương pháp này thường gặp nhiều khó khăn như tần suất thu mẫu cao kéo theo chi phí cao và chỉ đánh giá được chất lượng môi trường vào thời điểm thu mẫu, không đánh giá được những tác động tổng hợp và lâu dài của các chất ô nhiễm đối với sinh vật và hệ sinh thái.

Trong những thập niên gần đây, các loài hai mảnh vỏ được nhiều nhà khoa học nghiên cứu, sử dụng để quan trắc ô nhiễm KLN, do chúng có đời sống tĩnh; khả năng tích lũy KLN cao trong các bộ phận cơ thể mà không có biểu hiện gây hại cho chúng. Đây là phương pháp được đánh giá cao bởi nó khắc phục được những hạn chế của phương pháp 
phân tích lý hóa và nhận dạng sự có mặt của KLN trong môi trường ngay ở hàm lượng rất nhỏ mà các phương pháp phân tích thông thường không phát hiện được (Merlimi, 1965; Ferrington, 1983; Doherty, 1993; Oeatel, 1998; Revera, 2003) [9]; có thể cho biết những tác động trực tiếp của ô nhiễm đến sinh vật và hệ sinh thái (Thomas, 1975; Samoiloff, 1989),... [8].

Ở Việt Nam, việc sử dụng các loài hai mảnh vỏ để chỉ thị KLN được nghiên cứu bởi một số tác giả như: Lê Thị Vinh và cs. (2005; 2006) [6], [7]; Đặng Thúy Bình và cs. (2006) [3]... Tuy nhiên, việc ứng dụng phương pháp này vào quan trắc chất lượng môi trường nước còn. Trong nghiên cứu này, chúng tôi trình bày kết quả sự tích lũy $\mathrm{As}, \mathrm{Pb}$ ở hai loài Hến (Corbicula sp.) và Hàu sông (Ostrea rivularis G.) tại cửa sông $\mathrm{Cu}$ Đê, TP. Đà Nẵng.

\section{PHƯƠNG PHÁP NGHIÊN CÚU}

Đối tượng nghiên cứu là loài Hến (Corbicula sp.) thuộc họ Corbiculidae, bộ Mang tấm (Eulamellibranchia), lớp Hai mảnh vỏ (Bivalvia), ngành động vật Thân mềm (Mollusca) và loài Hàu sông (Ostrea rivularis G.) thuộc họ Ostreidae, bộ Mang sợi (Fillibranchia), lớp Hai mảnh vỏ (Bivalvia), ngành động vật Thân mềm (Mollusca) [2], [5].

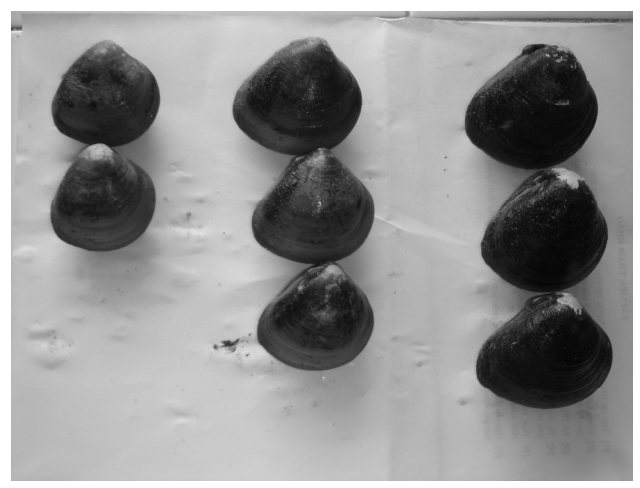

a

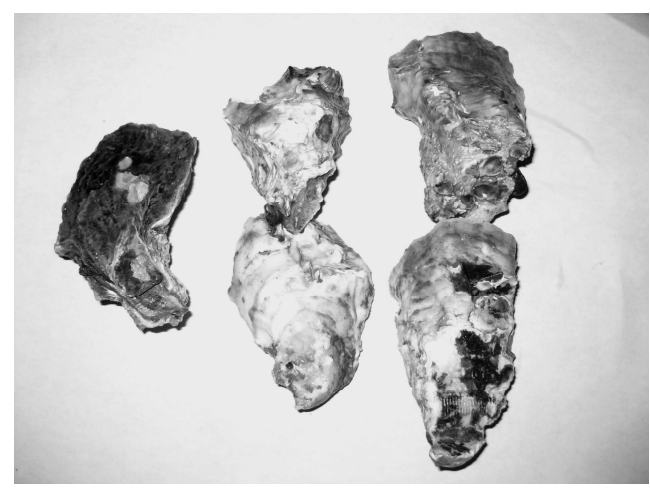

b

Hình 1: a. Loài Hến (Corbicula sp.); b. Loài Hàu sông (Ostrea rivularis G.)

Mẫu động vật được thu vào hai đợt: đợt 1 vào tháng 10 năm 2008 và đợt 2 vào tháng 2 năm 2009. Mẫu thu được bảo quản ở $4^{\circ} \mathrm{C}$ (theo M. Z. L. Goksu, 2003) [12]. Định loại mẫu theo khóa định loại hình thái của Thái Trần Bái, Đặng Ngọc Thanh, Phạm Văn Miên (1980). Mẫu bùn đáy được thu đồng thời với mẫu động vật và được bảo quản theo TCVN 6663-12:2000. 
Tiến hành vô cơ hóa phần mô mềm của mẫu động vật theo phương pháp của Van Loo, Dupreez và Steyn (2001) [11]. Mẫu bùn đáy được xử lý và tiến hành vô cơ hóa bằng $\mathrm{HNO}_{3}$ đặc và $\mathrm{H}_{2} \mathrm{O}_{2}$. Phân tích hàm lượng $\mathrm{As}, \mathrm{Pb}$ bằng máy quang phổ hấp thụ nguyên tử (AAS). Các số liệu được xử lý thống kê, so sánh các giá trị trung bình bằng phương pháp phân tích ANOVA và kiểm tra LSD với mức ý nghĩa $\alpha=0,05$, trong phân tích tương quan các giá trị được chuyển dạng theo công thức $\mathrm{x}^{\prime}=\log _{10}(\mathrm{x}+10)$.

\section{KẾT QUẢ VÀ THẢO LUẬN}

\section{Kích thước và khối lượng của hai loài Hến (Corbicula sp.) và Hàu sông (Ostrea rivularis G.)}

Qua hai đợt chúng tôi đã thu được 43 mẫu của loài Hến (Corbicula sp.) và 35 mẫu của loài Hàu sông (Ostrea rivularis $\mathrm{G}$.). Trong đó loài Hến có kích thước dao động từ 3,50 đến $5,10 \mathrm{~cm}$, trung bình: $4,33 \pm 0,42 \mathrm{~cm}$ và khối lượng trung bình: $29,30 \pm 1,07 \mathrm{~g}$, còn đối với loài Hàu sông có kích thước từ 3,90 đến $5,10 \mathrm{~cm}$, trung bình: $4,51 \pm 0,44 \mathrm{~cm}$ và khối lượng trung bình: $41,10 \pm 0,72 \mathrm{~g}$ (bảng 1).

\section{Hàm lượng $\mathrm{As}$, $\mathrm{Pb}$ trong bùn đáy, trong loài Hến (Corbicula sp.) và Hàu sông (Ostrea rivularis $\mathbf{G}$.)}

Hàm lượng As trung bình trong bùn đáy: 7,59 $\pm 3,24 \mu \mathrm{g} / \mathrm{g}$. So sánh với TC ISQG về giới hạn cho phép của As trong bùn đáy $(\leq 7,24 \mu \mathrm{g} / \mathrm{g})$ cho thấy, tại khu vực cửa sông $\mathrm{Cu}$ Đê có dấu hiệu ô nhiễm As. Trong khi đó hàm lượng $\mathrm{Pb}$ trung bình trong bùn đáy: 15,45 \pm $5,30 \mu \mathrm{g} / \mathrm{g}$, nằm trong giới hạn cho phép so với tiêu chuẩn ISQG ( $\leq 30,2 \mu \mathrm{g} / \mathrm{g})$ (bảng 2).

Hiện nay, các loài Hến và Hàu sông được nghiên cứu về khả năng tích lũy đối với hầu hết các KLN độc hại như $\mathrm{As}, \mathrm{Hg}, \mathrm{Cd}, \mathrm{Pb}, .$. Tuy nhiên, mức độ tích lũy đối với mỗi KLN là khác nhau. Kết quả ở nghiên cứu này cho thấy, hàm lượng As trung bình tích lũy ở loài Hến: $1,40 \pm 0,64 \mu \mathrm{g} / \mathrm{g}$ và Hàu sông: $1,23 \pm 1,08 \mu \mathrm{g} / \mathrm{g}$. Hàm lượng As tích lũy trong hai loài đều cao hơn tiêu chuẩn cho phép (TCCP) của Bộ y tế $(\leq 1 \mu \mathrm{g} / \mathrm{g})$. Hàm lượng $\mathrm{Pb}$ trung bình tích lũy trong loài Hến: $3,58 \pm 2,69 \mu \mathrm{g} / \mathrm{g}$ và Hàu sông: $1,04 \pm 0,81 \mu \mathrm{g} / \mathrm{g}$. Hàm lượng $\mathrm{Pb}$ trong loài Hến cao hơn TCCP của Bộ y tế $(\leq 2 \mu \mathrm{g} / \mathrm{g})$, còn đối với loài Hàu sông thì thấp hơn TCCP (bảng 3).

Kết quả phân tích ANOVA $(\alpha=0,05)$ cho thấy, không có sự khác nhau có ý nghĩa về mức độ tích lũy As giữa hai loài Hến và Hàu sông. Tuy nhiên, mức độ tích lũy $\mathrm{Pb}$ ở loài Hến lại cao hơn và khác nhau có ý nghĩa so với loài Hàu sông (bảng 3 , hình 2). 
Bảng 1: Kích thước $(\mathrm{cm})$, khối lượng $(\mathrm{g})$ của hai loài Hến và Hàu sông

\begin{tabular}{|c|c|c|c|c|}
\hline \multirow{2}{*}{} & \multicolumn{2}{|c|}{ Loài Hến } & \multicolumn{2}{c|}{ Loài Hàu sông } \\
\cline { 2 - 5 } & $\begin{array}{c}\text { Kích thước } \\
\mathbf{M} \pm \mathbf{S d}(\mathbf{c m})\end{array}$ & $\begin{array}{c}\text { Khối lượng } \\
\mathbf{M} \pm \mathbf{S d}(\mathbf{g})\end{array}$ & $\begin{array}{c}\text { Kích thước } \\
\mathbf{M} \pm \mathbf{S d}(\mathbf{c m})\end{array}$ & $\begin{array}{c}\text { Khối lượng } \\
\mathbf{M} \pm \mathbf{S d}(\mathbf{g})\end{array}$ \\
\hline Trung bình & $4,33 \pm 0,42$ & $29,30 \pm 1,07$ & $4,51 \pm 0,44$ & $41,10 \pm 0,72$ \\
\hline Minimum & 3,50 & 28,92 & 3,90 & 40,39 \\
\hline Maximun & 5,10 & 32,17 & 5,10 & 42,39 \\
\hline
\end{tabular}

Bảng 2: Hàm lượng $\mathrm{As}, \mathrm{Pb}$ trung bình trong bùn đáy

\begin{tabular}{|c|c|c|}
\hline Hàm lượng KLN & M $\mathbf{\text { Sd }}$ & TC ISQ (Canada) \\
\hline $\begin{array}{c}\mathrm{As}(\mu \mathrm{g} / \mathrm{g}) \\
(\mathrm{n}=8)\end{array}$ & $7,59 \pm 3,24$ & $\leq 7,24 \mu \mathrm{g} / \mathrm{g}$ \\
\hline $\begin{array}{c}\mathrm{Pb}(\mu \mathrm{g} / \mathrm{g}) \\
(\mathrm{n}=8)\end{array}$ & $15,45 \pm 5,30$ & $\leq 30,2 \mu \mathrm{g} / \mathrm{g}$ \\
\hline
\end{tabular}

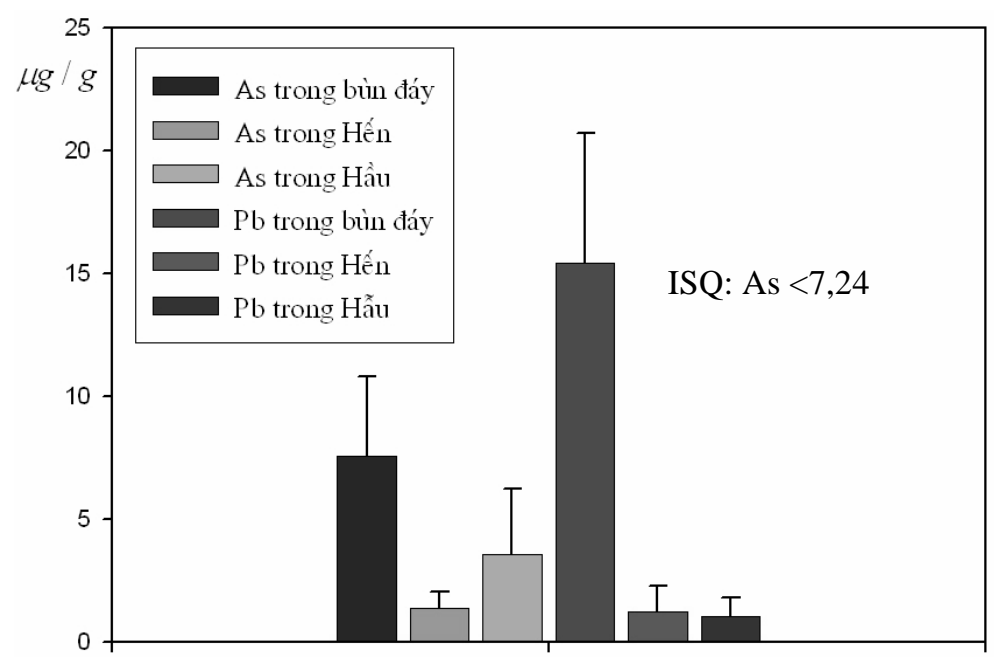

Hình 2: Hàm lượng $\mathrm{As}, \mathrm{Pb}$ tích lũy trong bùn đáy và trong hai loài Hến và Hàu sông 
Bảng 3: Hàm lượng $\mathrm{As}, \mathrm{Pb}$ trong hai loài Hến và Hầu sông

\begin{tabular}{|c|c|c|c|}
\hline \multirow{2}{*}{$\mathbf{K L N}$} & Hến & Hàu sông & TCCP \\
\hline & $\mathbf{M} \pm \mathbf{S d}$ & $\mathbf{M} \pm \mathbf{S d}$ & (867/1998/QĐ-BYT) \\
\hline As $(\mu \mathrm{g} / \mathrm{g})(\mathrm{n}=8)$ & $1,40 \pm 0,64 \mathrm{a}$ & $1,23 \pm 1,08 \mathrm{a}$ & 1 \\
\hline $\mathrm{Pb}(\mu \mathrm{g} / \mathrm{g})(\mathrm{n}=8)$ & $3,58 \pm 2,69 a^{\prime}$ & $1,04 \pm 0,81 b^{\prime}$ & 2 \\
\hline
\end{tabular}
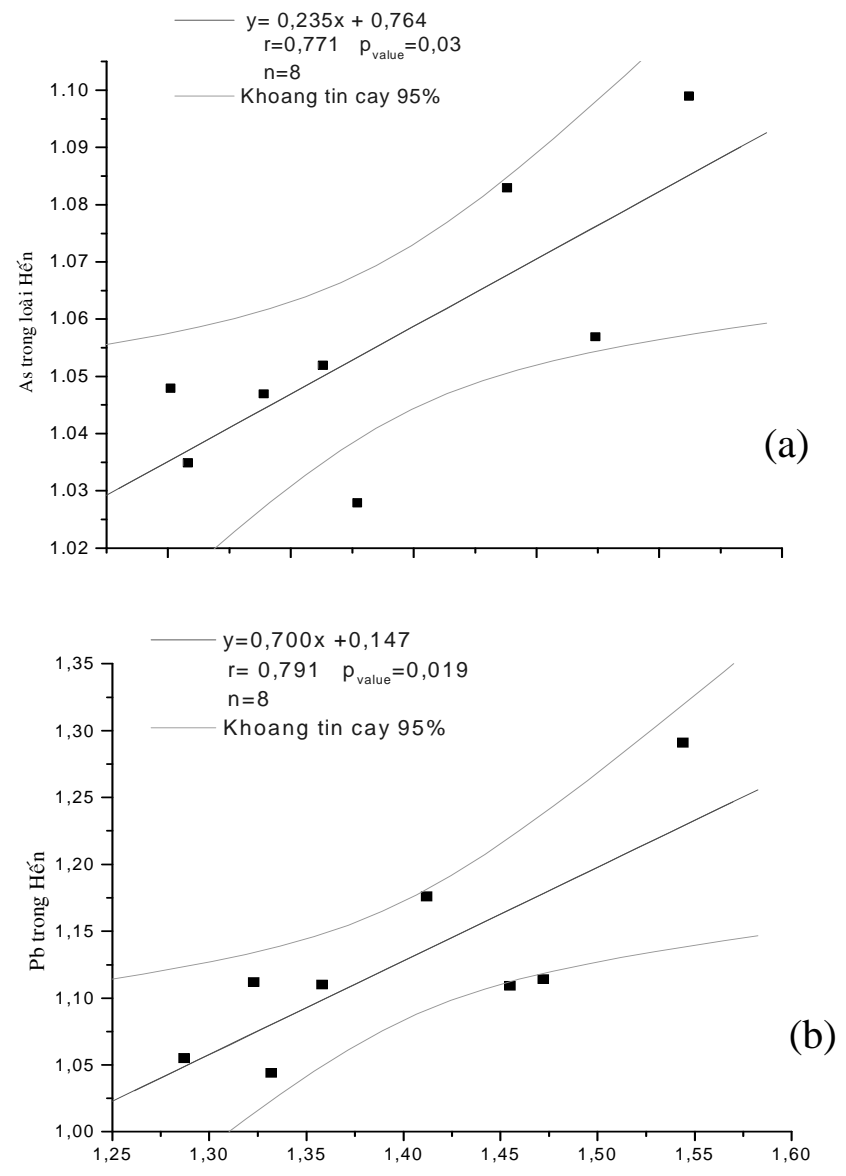

Hình 3: $\mathrm{a}, \mathrm{b}$. Tương quan giữa $\mathrm{As}, \mathrm{Pb}$ tích lũy trong bùn đáy và trong loài Hến (Corbicula sp.). Ghi chú: Các giá trị trung bình có cùng chữ cái $a, b$ và a', b’ không có sự khác nhau có ý nghĩa theo cột 


\section{Tương quan giữa hàm lượng $\mathrm{As}, \mathrm{Pb}$ trong bùn đáy và trong cơ thể Hến và Hàu sông}

KLN tích lũy trong mô các loài hai mảnh vỏ có nhiều nguồn gốc khác nhau. Theo Huanxin, Lejun (2000), Wang (2002), Apeti (2005), sự tích lũy này là do nước, bùn đáy, thức ăn bị ô nhiễm KLN. Kết quả phân tích tương quan giữa hàm lượng $\mathrm{As}$ và $\mathrm{Pb}$ trong bùn đáy và trong loài Hến và Hàu sông cho thấy, sự tích lũy $\mathrm{As}, \mathrm{Pb}$ trong hai loài Hến và Hầu sông tương quan thuận với sự tích lũy $\mathrm{As}, \mathrm{Pb}$ trong bùn đáy. Trong đó ở loài Hến sự tích lũy As ở mức "tương quan chặt" với $\mathrm{r}=0,771$ ( $\mathrm{p}_{\text {value }}=0,03$ ) (hình $3 \mathrm{a}$ ); sự tích lũy $\mathrm{Pb}$ ở mức "tương quan chặt" với hệ số tương quan $r=0,791$ ( $\mathrm{p}_{\text {value }}=0,019$ ) (hình $3 b$ ).
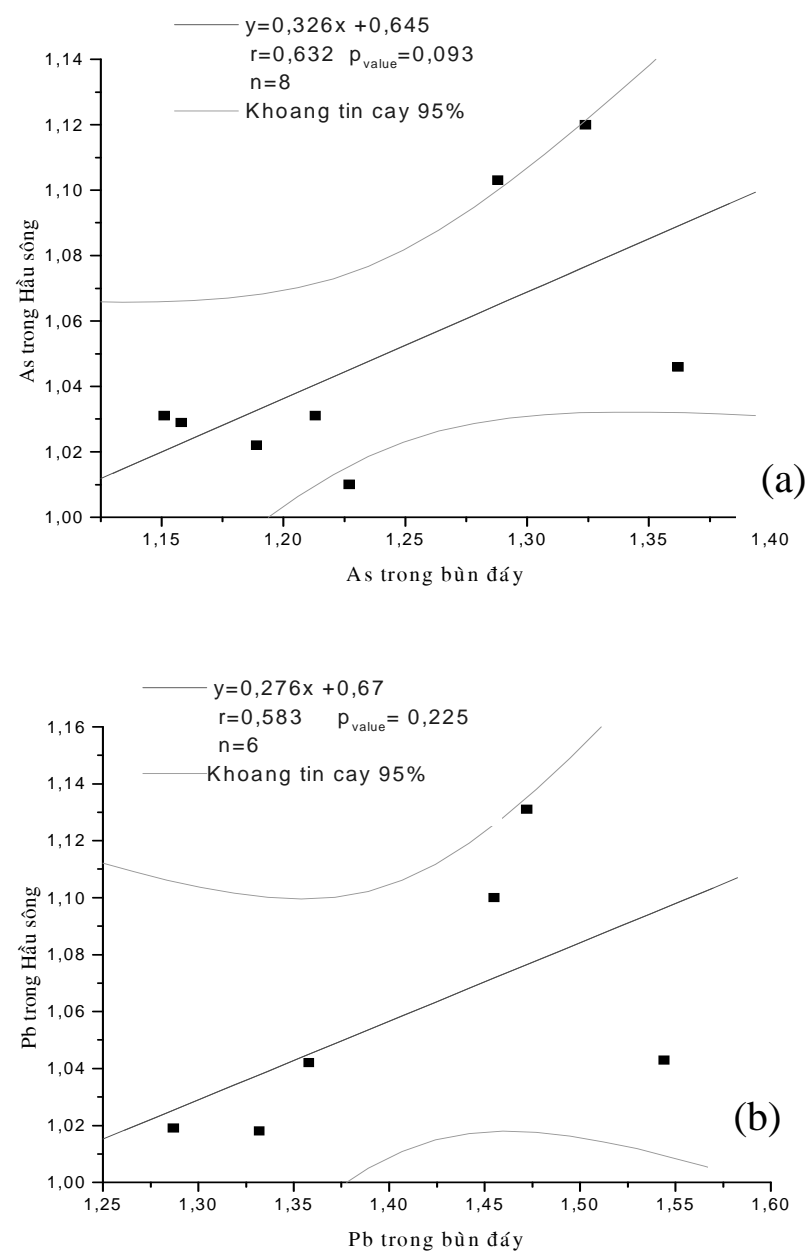

Hình 4: $\mathrm{a}, \mathrm{b}$. Tương quan giữa $\mathrm{As}, \mathrm{Pb}$ tích lũy trong bùn đáy và trong loài Hàu sông (Ostrea rivularis $\mathrm{G}$.) 
Ở loài Hàu sông sự tích lũy As tương quan ở mức "tương đối chặt" với $r=0,632$ $\left(\mathrm{p}_{\text {value }}=0,093\right)$ (hình $\left.4 \mathrm{a}\right)$, sự tích lũy $\mathrm{Pb}$ tương quan ở mức "tương quan yếu" với $\mathrm{r}=0,218$ $\left(\mathrm{p}_{\text {value }}=0,25\right)$ (hình $\left.4 \mathrm{~b}\right)$.

\section{KẾT LUẬN}

1. Bùn đáy ở khu vực sông $\mathrm{Cu}$ Đê $\mathrm{TP}$. Đà Nẵng hàm lượng As trung bình vượt TCCP 1,05 lần $(7,59 \pm 3,24 \mu \mathrm{g} / \mathrm{g})$, trong khi $\mathrm{Pb}$ chưa có dấu hiệu ô nhiễm $(5,45 \pm 5,30$ $\mu \mathrm{g} / \mathrm{g})$.

2. Hàm lượng As ở cả hai loài Hến và Hàu sông đều vượt TCCP của Bộ y tế (Hến: $15,45 \pm 5,30 \mu \mathrm{g} / \mathrm{g}$ và Hàu sông: $1,23 \pm 1,08 \mu \mathrm{g} / \mathrm{g}$ ). Điều đáng chú ý là mặc dù hàm lượng $\mathrm{Pb}$ trong bùn đáy của sông $\mathrm{Cu}$ Đê chưa có dấu hiệu ô nhiễm, nhưng hàm lượng $\mathrm{Pb}$ tích lũy trong loài Hến đã vượt TCCP 1,5 lần $(3,58 \pm 2,69 \mu \mathrm{g} / \mathrm{g})$. Hàm lượng $\mathrm{Pb}$ trong loài Hàu sông vẫn nằm trong $\mathrm{TCCP}(1,04 \pm 0,81 \mu \mathrm{g} / \mathrm{g})$.

3. Sự tương quan thuận giữa hàm lượng $\mathrm{As}, \mathrm{Pb}$ trong bùn đáy và trong loài Hến (Corbicula sp.) và loài Hàu sông (Ostrea rivularis G.) cho thấy có thể sử dụng hai loài này làm sinh vật chỉ thị cho ô nhiễm $\mathrm{As}$ và $\mathrm{Pb}$ trong khu vực cửa sông $\mathrm{Cu}$ Đê, TP. Đà Nẵng.

\section{TÀI LIỆU THAM KHẢO}

1. Lê Huy Bá, 2002. Độc học môi trường. NXB Đại học QG TP.HCM.

2. Thái Trần Bái, 2005. Động vật không xương sống. NXB Giáo dục.

3. Đặng Thúy Bình, Nguyễn Thanh, Sơn, Nguyễn Thị Thu Nga, 2006. Nghiên cứu sự tích lũy kim loại nặng trong ốc hương và một số đối tượng hải sản (Vẹm, Hải sâm, Rong sụn) tại đảo Điệp Sơn, vịnh Vân Phong, Khánh Hòa. Tạp chí Khoa họcCông nghệ Thủy sản, số 03-04/2006.

4. Lê Đức và cs, 2004. Một số phương pháp phân tích môi trường. NXB Đại học Quốc gia Hà Nội.

5. Đặng Ngọc Thanh, Thái Trần Bái, Phạm Văn Miên, 1980. Định loại động vật không xương sống nước ngọt Bắc Việt Nam. NXB Khoa học Kỹ thuật.

6. Lê Thị Vinh, 2005. Ảnh hưởng của hạt Nix từ nhà máy đóng tàu Hyundai-Vinashin tới hàm lượng kim loại trong Hàu Saccostrea cucullata vịnh Vân Phong. Phụ trương Tạp chí Khoa học và Công nghệ Biển, 198-204. 
7. Lê Thị Vinh, Phạm Văn Thơm, Nguyễn Hồng Thu, Dương Trọng Kiểm, Phạm Hữu Tâm, 2006. Ảnh hưởng của $\mathrm{Zn}$ và $\mathrm{Cu}$ từ hạt $\mathrm{Nix}$ của nhà máy đóng tàu Hyundai-Vinashin tới chất lượng môi trường Mỹ Giang, vịnh Vân Phong. Tuyển tập nghiên cứu Biển, 2006, XV, 81-91.

8. John ogony Odiyo, Hendricks Maboladisoro Bapele, Ronal Mugwedi and Luke Chimuka, 2005. Metal in environmental media: A study of trace and plantinum group metals in Thoyaandou, South Africa. School of Environmental Sciences and Engineering, University of Vende, South Africa.

9. Perey Perera, 2004. Heavy metal concentrations in the Pacific Oystre Crassostrea gigas, Auckland University of Technology, Auckland.

10. Sari Airas, Trace metal concentrations in blue mussel Mytilus edulis in Byfiorden and the coastal areas of Bergen, Institute for Fisheries and Marine Biology University of Bergen.

11. Avenant, Oldewage and $\mathrm{HM}$ Marx, 2006. Bioaccumulation of $\mathrm{Cd}, \mathrm{Cu}, \mathrm{Fe}$ in the organs and tissues of Clarias gariepinus in the Olifants River, Kruger National park. Departmnet of Zoology, Rond Afrikaans University, PO box 524, Auckland Park, South Africa.

12. Munir Ziya Lugal Goksu, Muatafa Akar, Fatma Cevik, Ozlem Findik, 2003. Bioaccumulation of Some Heavy metals (Cd, Fe, $\mathrm{Zn}, \mathrm{Cu}$ ) in two Bivalvia Species (Pinctada radiate Leach, 1814 and Brachidontes pharaonis Fischer, 1870), Turk Vet Anim Sci 29 (2005).

\section{ACCUMULATION OF As, Pb IN CLAM (Corbicula sp.) AND RIVER OYSTER (Ostrea rivularis Gould, 1861) IN CU DE ESTUARINE, DA NANG CITY}

\section{NGUYEN VAN KHANH, VO VAN MINH, PHAM THI HONG HA, DUONG CONG VINH}

Summary: Bivalves are widely regarded as good bioindicator species because of their widespread distribution and abundance in many aquatic habitats. They have sedentary life, hardiness and ability to bioaccumulate from water and sediments. Bivalves have been studied to indicate the pollution of heavy metal in environment. Besides the technical facilities to determine metal concentration in organisms, usually higher than that of the other components, represent the amount of metals bioavailability and thus possibly going into food chain with possible toxic and deleterious impacts to the ecosystem. In this study, we present the studied results about concentration of As, Pb in Clam (Corbicula sp.) and Oyster (Ostrea rivularis G.) 
from $\mathrm{Cu}$ De estuarine, Da Nang city. Our data have important implications for biomonitor of heavy metal by Clam (Corbicula sp.) and Oyster (Ostrea rivularis G.).

Ngày nhận bài: 25 - 10 - 2009

Ngưòi nhận xét: PGS. TS. Nguyễn Tác An 